\section{Orange and pineapple wastes as potential substrates for citric acid production}

\author{
Olubukola Omoniyi Kuforiji, ${ }^{1}$ \\ Adunola Oluseye Kuboye, ${ }^{2}$ \\ Sunday Ayodele Odunfa ${ }^{3}$ \\ 'Bells University of Technology, Ota, \\ Ogun State, Nigeria
}

${ }^{2}$ Federal Institute of Industrial Research, Oshodi, Lagos State, Nigeria

${ }^{3}$ University of Ibadan, Department of Botany and Microbiology, Ibadan, Oyo State, Nigeria

\begin{abstract}
Orange (pulp) and pineapple wastes were used as substrates for citric acid production by two strains of Aspergillus niger. A. niger strains NRRL 567 and 328 produced the maximum amount of citric acid (57.6\% and $55.4 \%$, respectively) at a moisture content of $38.9 \%$ in orange waste and the highest yields of $46.4 \%$ and $45.4 \%$ citric acid in pineapple waste at moisture contents of $54.4 \%$ and $63.4 \%$, respectively. The addition of $1-3 \%$ methanol to the substrates resulted in reduction in yield in both cases.
\end{abstract}

\section{Introduction}

The production of citric acid using microorganisms growing in surface culture began in the 1930s. ${ }^{1}$ Citric acid is used in the food and beverage industry to flavor fruit juices, candy ice cream, and marmalade. In the pharmaceutical industry, citric acid is used as a preservative for stored blood, tablets, ointments, and cosmetic preparations. ${ }^{2}$ In the chemical industry, it is used as an antifoam agent and for the treatment of textiles. Today over $99 \%$ of the world's output is produced using Aspergillus niger, A. wentii, A. clavatus, Penicillium luteum, $P$. citrinum, Mucor piriformis, Candida guilliermondii, Saccharomycopsis lipolytica, Trichoderma viride, and Arthrobacter paraffineus.${ }^{34}$ However, only mutants of $A$. niger and the closely related strain of $A$. wentii are used for commercial production. The use of sucrose, starch from various sources, cane and beet molasses, and apple pomace for citric acid production has been reviewed by Kapoor et al. ${ }^{1}$ Apple pomace has been used as an energy source in alleviating the waste disposal problems. ${ }^{5}$ Normally strains of $A$. niger need a high concentration of sugars (15-18\%) in the medium. The initial moisture content of apple pom- ace was reported to affect the fungal production of citric acid in a solid state fermentation system and the addition of $4 \%$ methanol increased the yield to $88 \%{ }^{6,7}$ Orange and pineapple wastes are dumped indiscriminately after extracting the edible portion and this uncontrolled activity leads to environmental pollution with the resultant health hazard to the populace. Thus, we carried out studies on the suitability of orange and pineapple wastes as substrates for the production of citric acid, on the effect of the initial moisture content of substrates on the yield of citric acid, and on the effect of methanol on the yield of citric acid, using A. niger strains NRRL 567 and 328.

\section{Materials and Methods}

Citric acid producing strains of $A$. niger, NRRL 567 and 328, were obtained from Dr. C.W. Hesseltine, Northern Regional Research Center, IL., USA. Each culture was grown on a potato dextrose agar slant at $28^{\circ} \mathrm{C}$ for 7 days. A spore inoculum was prepared by adding $3 \mathrm{~mL}$ of sterile distilled water to each slant and shaking for $1 \mathrm{~min}$; this was referred to as suspension of the fungus. The number of spores was counted to be $2 \times 10^{5} \mathrm{cfu} / \mathrm{mL}^{6}{ }^{6}$

\section{Determination of the substrates' moisture content}

Pineapple waste was obtained as a residue from juice extraction of the fresh fruit and, having an initial moisture content of $79.6 \%$, was dried to a moisture level of $14.7 \%$ (the control). To each portion of $20 \mathrm{~g}, 2.5 \mathrm{~mL}, 5.0 \mathrm{~mL}$, $7.5 \mathrm{~mL}, 10 \mathrm{~mL}$ and $15 \mathrm{~mL}$ of a liquid medium containing $0.25 \mathrm{~g} / \mathrm{L} \mathrm{NH}_{4} \mathrm{NO}_{3}$ and $0.16 \mathrm{~g} / \mathrm{L}$ $\mathrm{KH}_{2} \mathrm{PO}_{4}$ were added. The same procedure was carried out using the orange waste (i.e. the pulp). In both cases, a control in which no liquid medium was added was set up, and the moisture content in all cases was determined using the Sartorius MA30 Moisture Analyser. Sterilization was carried out at $10 \mathrm{lbs} / 30$ mins. The flasks were cooled and inoculated with 1 mL suspension of $A$. niger strains NRRL 567 and 328 , respectively. Then they were incubated at $28^{\circ} \mathrm{C}$ for 6 days. In all cases the determination was carried out in triplicate.

\section{Effect of different concentrations of methanol on the yield of citric acid}

One milliliter of each of the suspensions of A. niger strains NRRL 567 and 328 , previously grown on potato dextrose agar slant at $28^{\circ} \mathrm{C}$ for 7 days, was added to pineapple and orange wastes each in a conical flask. Methanol was added at a level of 1-5\% (v/v) to each flask before fermentation. The flasks were incubated at $28^{\circ} \mathrm{C}$ for 6 days.
Correspondence: Olubukola Kuforiji, Bells University of Technology, P.M.B.1015, Ota, Ogun State, Nigeria.

E-mail: bukkolak@yahoo.com

Key words: substrates, citric acid, moisture content, yield.

Acknowledgements: the authors are grateful to the management of the Federal Institute of Technology, Oshodi, Lagos, Nigeria for the opportunity to carry out this work, and to Mr. J. Ogunjimi for supplying the orange and pineapple wastes.

Received for publication: 17 August 2009

Revision received: 22 December 2009

Accepted for publication: 22 December 2009

This work is licensed under a Creative Commons Attribution 3.0 License (by-nc 3.0).

(C) Copyright Kuforiji Olubukola et al., 2010

Licensee PAGEPress, Italy

International Journal of Plant Biology 2010; 1:e4 doi:10.4081/pb.2010.e4

\section{Analyses of fermented materials}

In all cases, the fermented materials were extracted with distilled water and the extracts were analyzed for reducing sugar as glucose and citric acid, using dinitrosalicylic acid and pyridine-acetic acid methods, respectively. ${ }^{8}$ The yield of citric acid was expressed as: weight of acid produced/weight of glucose used. $^{9}$

\section{Statistical analyses}

In each case, the determination was carried out in triplicate. Means were quoted with their standard errors (S.E.) and analyses were done using analysis of variance. ${ }^{10}$

\section{Results and Discussion}

The orange and pineapple wastes had initial moisture contents of $82.3 \%$ and $79.6 \%$, and $\mathrm{pH}$ of 5.4 and 4.1, respectively. On drying and rehydrating the orange waste with sterile distilled water, the substrates gave values as indicated in Figure 1. Maximum yield values of $55.4 \%$ and $57.6 \%$ citric acid were obtained using $A$. niger strains NRRL 328 and 567 at moisture levels of $22.5-38.9 \%$. In pineapple waste, the yields of citric acid produced were $46.4 \%$ and $45.4 \%$ at moisture contents of $54.8 \%$ and $63.4 \%$, using strains NRRL 328 and 567, respectively (Figure 2). Thus, it can been inferred that there is no significant difference in the yield obtained using the two strains of $A$. niger, and orange waste seems to be a better 

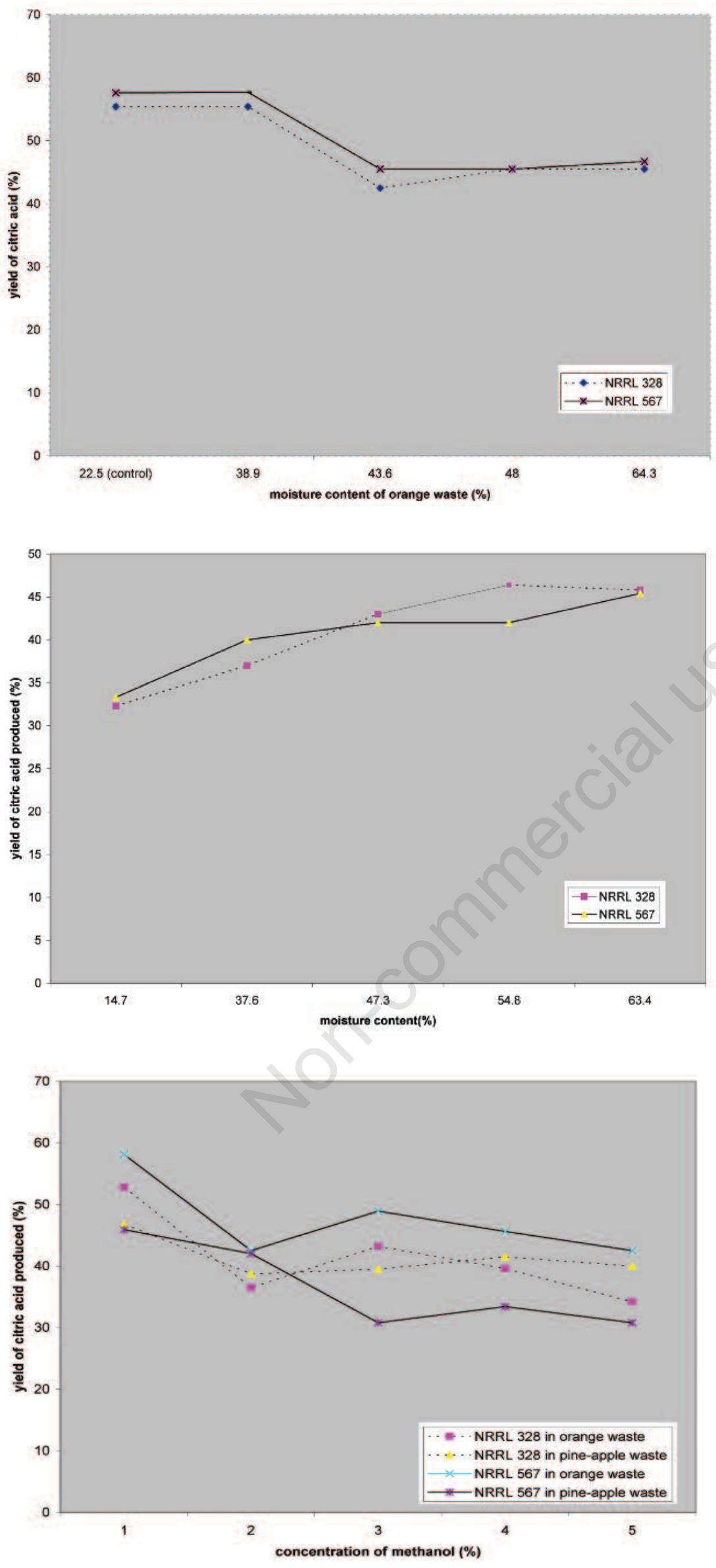

Figure 1. The effect of moisture content of orange waste on fungal production of citric acid. Values are means of triplicate determinations. $F_{0.05}=1.2 ; F_{0.01}=2.0$. Mean S.E. differences higher than $F_{0.05}$ and $F_{0.01}$ are significant at $5 \%$ and $1 \%$ levels, respectively.
Figure 2. The suitability of pineapple waste as a substrate for citric acid production by $A$. niger. Values are means of triplicate determinations. $F_{0.05}=1.2 ; F_{0.01}=2.0$. Mean S.E. differences higher than $F_{0.05}$ and $F_{0.01}$ are significant at $5 \%$ and $1 \%$ levels, respectively.
Figure 3. The effect of methanol on the yield of citric acid using orange and pineapple wastes as substrates. Values are means of triplicate determinations. $F_{0.05}=1.2 ; \quad F_{0.01}=\mathbf{2 . 0}$. Mean S.E. differences greater than $F_{0.05}$ and $F_{0.01}$ are significant at $5 \%$ and $1 \%$ levels, respectively. 
substrate for citric acid production than pineapple waste (Figures 1 and 2). No difference was observed in the yield of citric acid produced on orange waste at moisture levels of $22.5-38.9 \%$ and the amount of the acid produced decreased with increase in moisture content, while in pineapple waste there were significant increases in the yield from $32.3 \%$ to $46.4 \%$ and $33.3 \%$ to $45.4 \%$, using $A$. niger strains NRRL 328 and 567, respectively. Strain NRRL 567 gave a higher yield of citric acid in orange waste, while strain NRRL 328 performed better in pineapple waste. Hang and Woodams ${ }^{7}$ reported that NRRL 567 gave much higher yields of citric acid from apple pomace than $A$. niger NRRL 328 (60\% and 80\%, respectively) at moisture contents of $65-75 \%$.

The effect of methanol in increasing citric acid yields appears to be a general phenomenon in strains of $A$. niger and the use of methanol has become a common practice in citric acid production. ${ }^{1}$ In both strains of $A$. niger there was a significant decrease in yield of citric acid produced with increase in concentration of methanol added to the substrates (i.e. the orange and pineapple wastes) (Figure 3 ). Thus, it can be concluded that methanol may not always have a stimulatory effect on fungal production of citric acid. However, the yield of citric acid produced in orange and pineapple wastes is low still when compared to using apple pomace (88\%), kiwifruit peel $(75 \%)$, and sugar cane bagasse $(80-85 \%){ }^{11}$ Kiel et $a l .{ }^{12}$ noted that the mycelium obtained from surface culture in cotton waste medium yielded more citric acid when transferred into a sucrose containing medium than when inoculated into a sucrose containing medium; thus, there is a possibility of the two strains of $A$. niger performing better when transferred into a sucrose containing medium.

We concluded that orange and pineapple wastes have a potential use as substrates in fungal production of citric acid and the addition of methanol did not increase the yield of citric acid produced.

\section{References}

1. Kapoor KK, Chandhary K, Tauro P. Citric acid. In: Prescott and Dunn's Industrial Microbiology. 4th edn. Reed G, editor. Westport: AVI, 2004, pp.709-747.

2. Penniston KL, Nakeda SY, Holmes RP, et al. Quantitative assessment of citric acid in lemon juice, lime juice and commercially available juice products. J Endourol 2008;22: 567.

3. Roehr M, Kubicek CP, Kominek J. Citric Acid. In: Biotechnology. Vol. 3. Rehm HJ, Reeds G, editors. Weinheim: Verlag Chemie, 1983, pp. 341-52.

4. Wojtatowicz M, Rymowicz W, Kautola H. Comparison of different strains of the yeast Yarrowia lipolytica for citric acid production from glucose hydrol. Appl Biochem Biotechnol 1991;31:165-74.

5. Jewell WJ, Cummings RJ. Apple pomace: Energy and solids recovery. J Food Sci 1984; 49:407-10.

6. Hang YD, Woodams EE. Apple pomace: A potential substrate for citric acid production by Aspergillus niger. Biotechnol Lett 1984; 6:763-4.

7. Hang YD, Woodams EE. Effect of substrate moisture content on fungal production of citric acid in a solid state fermentation system. Biotechnol Lett 1987;9:183-7.

8. Marier JR, Boulet M. Direct determination of citric acid in milk with an improved pyridineacetic anhydride method. J Dairy Sci 1958;41:1683-9.

9. Riviere J. Industrial applications of Microbiology. Guildford: Surrey University Press, 1977, pp.151-96.

10. Sokal R, Rohlf F. Biometry. San Francisco: Freeman, 1995, pp.204-52.

11. Lakshminarayana K, Chaudhary K, Ethiraj $S$, et al. A solid state fermentation for citric acid using sugar cane bagasse. Biotechnol Bioeng 1975;17:291-3.

12. Kiel H, Guvrin R, Henis Y. Citric acid fermentation by Aspergillus niger on low sugar concentrations and cotton waste. App Environ Microbiol 1981;42:1-4. 